\title{
Special Issue Robótica 2014
}

\author{
Nuno Lau • António Paulo Moreira • \\ Rodrigo Ventura · Brígida Mónica Faria
}

Published online: 16 September 2015

(C) Springer Science+Business Media Dordrecht 2015

This special issue presents extended and revised versions of a selection of papers presented on the IEEE International Conference on Autonomous Robot Systems and Competitions (ICARSC-2014), that took place 14-15 May 2014 in the city of Espinho, Portugal. The conference was sponsored by the Sociedade Portuguesa de Robótica (SPR), IEEE Portugal Section, IEEE Portugal Section RA Chapter, and IEEE Robotics and Automation Society (RAS) This conference is collocated with the Portuguese Robotics

N. Lau $(\bowtie)$

Department of Electronics, Telecommunications, and Informatics, University of Aveiro, Aveiro, Portugal

e-mail: nunolau@ua.pt

\section{A. P. Moreira}

PDEEC, Faculty of Engineering, University of Porto, and with INESC TEC, Rua Dr. Roberto Frias s/n, 4200-465,

Porto, Portugal

e-mail: amoreira@fe.up.pt

R. Ventura

Institute for Systems and Robotics, Instituto Superior

Técnico, Universidade de Lisboa, Lisboa, Portugal

e-mail: rodrigo.ventura@isr.tecnico.ulisboa.pt

\section{B. M. Faria}

School of Allied Health Technologies, Polytechnic Institute of Porto (ESTSP/IPP), Vila Nova de Gaia, Portugal e-mail: btf@estsp.ipp.pt
Open - Festival Nacional de Robótica 2014, a scientific event including a broad range of competitions involving a large amount of both university and high school level students.

The keynote session opened the conference with Prof. Dr. Marco Dorigo, co-director of the IRIDIA lab and faculty in the Université Libre de Bruxelles, Belgium, as speaker, presenting a talk entitled "The Swarm-bots and Swarmanoid Experiments in Swarm Robotics" In this talk, Prof. Dr. Marco Dorigo presented an update on his recent research work, as well as the state of the art in swarm robotics.

In response to the conference Call for Papers, a total of 87 submissions were received, from which 34 papers were selected as full papers with oral presentation, and 22 for short paper with poster presentation. This corresponds to an acceptance ratio of $64 \%$ (39\% for full and $25 \%$ for short paper). The review process was double blind, where all papers were reviewed by at least 3 reviewers

The authors of the 21 best ranked papers, according to the reviews for the conference, were invited to submit extended versions of their papers to this Special Issue. An additional of $30 \%$ novel content was set as a requirement for these re-submissions. We received 19 submissions, and after a rigorous review process, where all papers were reviewed by at least 2 reviewers, 18 papers were accepted for publication in this Special Issue. These papers cover a broad range of active 
research areas in robotics, including wheeled, biped, aerial, and underwater robots.

The guest editors of this special edition are grateful both to the authors of the included papers for their contributions, and to the reviewers for their insightful and thorough reviews.
The Guest Editors

Nuno Lau

António Paulo Moreira

Rodrigo Ventura

Brígida Mónica Faria 